\title{
An Investigative and Comprehensive Study about Deregulation (Restructuring) of Indian Power Market
}

\author{
Ravindrakumar Yadav ${ }^{1^{*}}$, Ashok Jhala ${ }^{2}$ \\ ${ }^{1}$ Babaria Institute of Technology, Varnama, Vadodara, Gujarat, India \\ ${ }^{2}$ RKDF College of Engineering, Bhopal, India \\ e-mail: rkyadav.bit@gmail.com* , ravindrayadav.ee@bitseducampus.ac.in
}

\begin{abstract}
This paper is a discussion about the introduction of restructuring and deregulation in Indian Power System. In modern era, deregulation has an important impact on power sector. In this paper, recent use of deregulation in Indian Power Sector has been described and measures to be taken in order to improve deregulation are also suggested.
\end{abstract}

Keywords: deregulation, restructuring, Power Sector, CERC, TSO , LDC

\section{Introduction}

In current time, due to rise in power demand and supply, it is not an easy task to manage the generation and cost concurrently for one single party. To reduce monopoly of one organization and to provide quality and continue reliable power supply at reasonable cost, it is essential to encourage competition in power market. This can be possible by introducing restructuring and deregulation in electrical power sector.

Deregulation involves unbundling of different components of power system, availability of components for sale and also forming new set of rules for operation and sales of electricity [1].

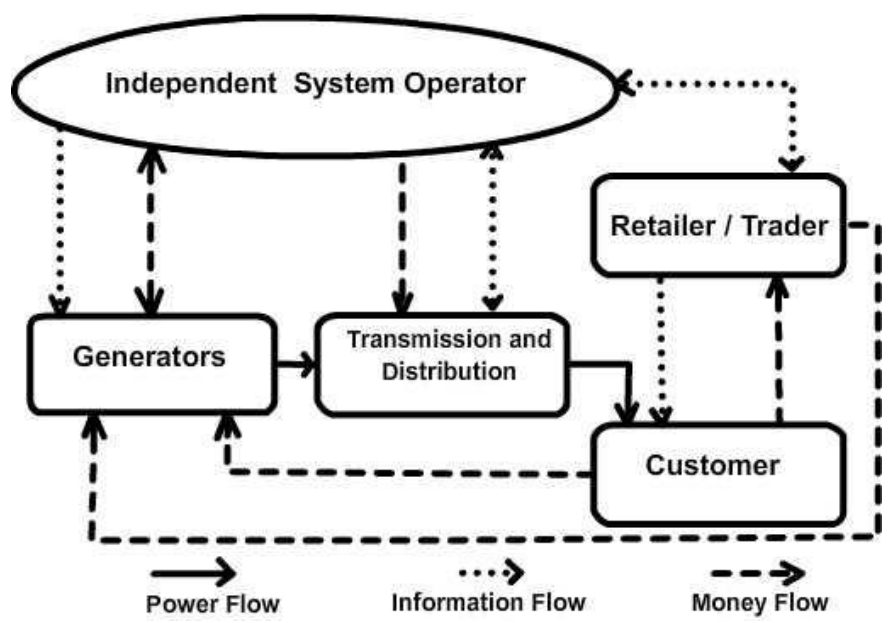

Figure 1. Deregulated power system

An main and important aspect of deregulation is restructuring. Restructuring means unbundling of power system into both horizontal and vertical components. Vertical integrated utilities are mainly broken up into three main components, i.e. Generation, Transmission and Distribution [2]. This introduces competition in generation, transmission open access with retail competition in distribution. Competition in generation reduces cost of power, Transmission open access provides access to transmission grid for the various generations, that enhances reliability of power supply. Retail competition in distribution provides choices for buyers to select 
between power suppliers, which provides good quality of power. The general structure of deregulated power system is shown in Figure 1.

Many countries like England, United States of America, Canada, Australia, Peru, New Zealand, Chile, Argentina, Colombia and Scandinavian have already adopted deregulated power structure since long[3]. In India, till independence the entire power sector was under the control of private sector. After the enactment of new Electricity Act in 1948, the entire power sector is mostly owned by State Governments and is largely managed by vertically integrated electricity business through State Electricity Boards (SEBs). In 1975, Government of India (GOI) entered in the field of generation and transmission through their Central sector power stations and management. However, distribution sector continued to stay with SEBs as a monopoly business. Over the period of operations, regrettably, the sector developed techno-comm inefficiencies. Restructuring therefore was felt as mandatory option to cure. Accordingly, the power generation was opened up in 1991 followed by transmission in 1998. Electricity Regulatory Commissions Act was enacted in 1998 for establishing regulatory commissions in various States. And then the Electricity Act 2003 has been notified by Government of India in June 2003. The objective of this act is to accelerate the power sector reforms.

\section{Power Sector Reforms}

The Government of India has been taking several initiatives to invite private sector participation in generation and transmission. Understanding the difficulties faced in the process of reforms, GOI in consultation with the States initiated measures to unblock the difficulties

1. Unbundling of SEB: A number of States have initiated the power sector reform process, starting the unbundling, tariff rationalization and corporatization of generation, transmission and distribution. Practically this brings the accountability at each level of operations in the power business. The results were not much encouraging although not so adverse to consider. Self-sustainability is not achieved through this makeup unless privatization is introduced in stages starting from urban areas.

2. Setting up of Regulatory Mechanism: The Central Electricity Regulatory Commission (CERC) along with State Electricity Regulatory Commissions (SERC) have been established in 19 states under the Electricity Regulatory Commissions Act, 1998, to discharge the following functions:

a. Regulation of the tariff of generating companies owned or controlled by the Central Government.

b. Regulation of the tariff for generating companies other than those owned or controlled by the Central Government if such generating companies enter into or otherwise have a composite scheme for generation and sale of electricity in more than one State.

c. Regulating the Inter-State transmission of energy including tariff of the transmission utilities.

d. Promoting competition, efficiency and economy in the activities of the electricity industry.

e. Advising the Central Government in the formulation of tariff policy which shall

(i) Provide justice to clients

(ii) Facilitate mobilization of adequate resources for the power sector.

f. Association with the environmental regulatory agencies to develop appropriate policies and procedures for environmental regulation of the power sector.

g. Framing of guidelines in matters relating to electricity tariff.

h. Resolving the disputes involving generating companies or transmission utilities.

i. Assisting Government of India on any other matter referred to the Central Commission by that Government.

j. Licensing any person for the construction, maintenance and operation of Inter-State transmission system.

\section{Regional Electricity Boards in India}

As per the statute, the Central Electricity Authority (CEA) is possible for power planning at the national level. CEA advises the Ministry of Power on the national power policy and 
planning, whereas the central electricity regulatory commission is looking after the regulatory issues. Day-to-day operation of the regional grid is carried out by Regional Load Dispatch Centers (RLDCs), which are under the operational control of CTU, i.e. PGCIL.

The main function of RLDC is, to carry out the integrated operation of the power system in that region and that of Regional Electricity Board (REB), to facilitate integrated grid operation. Presently five REBs namely, Northern REB, Southern REB, Western REB, Eastern REB and North-Eastern REB exist to promote the integrated operation of the regional power systems. The responsibilities of REBs are to review project progress, to plan integrated operation among the utilities in the region, to co-ordinate the maintenance schedules, to determine the availability of power for inter- state utilities transfer, to prescribe the generation schedule and to determine a suitable tariff for the inter-utility exchange of power. Power sector across the world is undergoing a lot of restructuring; India is no exclusion to this. The need for restructuring the power sector was felt due to the lack of financial resources available with Central and State Governments, and necessity of improving the technical and commercial efficiency.

In some States of India there are multiple private utilities, which are technically and financially in a position to enter the phase of a competitive electricity market. Hence, in 1998 the Regulatory Commissions were formed under the Electricity Regulatory Commissions Act 1998 (Central Law) to promote competition, efficiency and economy in the activities of the electricity industry. Ministry of Power has undertaken Accelerated Power Development and Reform Program (APDRP) from the year 2000-01 with the twin objectives of financial turn-around in the performance of the power sector especially in electric distribution and improvement in quality of supply.

Electricity Act 2003 has come into force from June 2003. As the act allows third party sales, it allows the concept of trading bulk electricity. The act also provides open access to transmission as well as distribution of electricity.

\section{Proposed Model for Restructuring in India}

In many parts of the world everywhere unbundling taken place, the two models are more established for system operation. The first one is Independent System Operator (ISO) model and the other is Transmission System Operator (TSO) model. In ISO model, transmission companies are also permitted to own, manage and control generation and distribution companies, an independent system operator is created to facilitate open access and competitive markets.

In TSO model, operation of the grid and ownership of the grid are integrated in a single entity, which is responsible for development of transmission system and to provide unbiased open access to all eligible market participants.

Neutrality is an important feature of the TSO to ensure an efficient market. In view of this, TSO model seems to be most suitable for future restructured electricity market in India. This is because the government owned Transmission Company is merely responsible to provide non-discriminatory open access. Some of the developed countries are also moving away from ISO model by formation of Regional Transmission Organizations (RTO), which will finally converge as a TSO model. Even though the conditions in Indian power market are not yet ripe for introducing retail competition, the necessities in a deregulated power market can be summarized below:

a. Non-discriminatory open access to transmission network is a pre-requisite for ensuring competition in wholesale power trading.

b. The system operation functions at the national level can be handled by central transmission utility while state transmission utilities can manage State Load Dispatch Centers (SLDCs) similar to TSO concept.

c. The regional electricity boards will have the responsibility of managing the power exchanges while the Regional Load Dispatch Centers (RLDCs) will manage the overall integrated operation of power system like outage planning, relay coordination, islanding schemes, etc. 


\section{Competing Models for Restructuring in India}

a. Odisha Model:

Orissa was the first state to embark on the reform program after the state Electricity Reform Act became effective in April 1996. Almost immediately, the Orissa State Electricity Board is partially unbundled into three separate entities: Orissa Hydro Power Corporation OHPC, Orissa Power Generation Corporation OPGC and Grid Corporation of Orissa GRIDCO. Generation was first privatized in June 1998, AES purchases 49\% stake in OPGC. In the second phase, the distribution assets, properties and personnel of GRIDCO is broken into four distribution companies. BSES purchases three of them (NESCO, WESCO and SOUTHCO) in April 1999 and one (CESCO) is transferred to AES Transpower (joint venture of AES and Jyothi Structures Ltd) in September 1999.

b. Delhi Model:

The Delhi Electricity Reform Act comes into force in March 2001. Two months later, Delhi Vidyut Board DVB, the state's electricity board, establishes six shell companies (holding company, generating company, Transmission Company, three distribution companies) to be operational. Distribution is first privatized. $51 \%$ of the equity in three distribution companies is sold to two privately owned Indian power companies, BSES and Tata Power. DVB ceases to exist and is replaced by the holding company, the Generation Company and Transmission Company. Delhi government retains ownership of the generation. Holding company retains all unserviceable liabilities. Existing serviceable DVB liabilities will be paid by successor agency after a four year grace period Introduced concept of aggregate technical and commercial (AT\&C) losses, rather than transmission and distribution (T\&D) losses. Private investors bid for distribution companies on the basis of a five year AT\&C targets, indicative multi-year tariff profile and projected Government assistance, a five year in-between period with some Government support over the period.

c. Andhra Pradesh Model:

State Reforms Act came into force w.e.f. Feb 1999. APSEB unbundled into Andhra Pradesh Generation Company Ltd. (APGENCO) and Andhra Pradesh Transmission Company Ltd. (APTRANSCO for transmission and distribution). Andhra Pradesh Electricity Regulatory Commission has been operational w.e.f. April 1999.

d. Haryana Model:

State Reforms Act came into force w.e.f. 14.8.1998. SERC became operational w.e.f. 17.8.1998. SEB unbundled into Haryana Vidyut Prasaran Nigam Ltd., a Trans Co. (HVPNL) and Haryana Power Corporation Ltd. On 14.8.1998. Two Government owned distribution companies viz. Uttar Haryana Bijli Vitaran Nigam Ltd.(UHBVNL) and Dakshin Haryana Bijli Vitaran Nigam Ltd.(DHBVNL) have been established. Till these two companies become independent licensees, they will operate as subsidiaries of HVPNL.

e. Uttar Pradesh Model:

State Reforms Act has been notified on 15.1.2000.As per the decision of the Government of Uttar Pradesh, the activities of generation, transmission and distribution of erstwhile UPSEB have been transferred to: Uttar Pradesh Rajya Vidyut Utpadan Nigam Ltd. (UPRVUNL) ,Uttar Pradesh Jal Vidyut Nigam Ltd. (UPJVNL) ,Uttar Pradesh Power Corporation Ltd. (UPPCL)- UPPCL took over the transmission and distribution functions of erstwhile UPSEB. Re-organization Committee set up to study the State Power Sector has submitted its recommendations to State Govt. The State Government has set up State Rural Energy Development Corporation as an independent company under the Companies Act to manage distribution for rural and agricultural consumer segments with assistance of Rural Energy Cooperatives. Consultants have submitted the final report of the tariff rationalization study which has been financed by PFC. Four Task Forces have been formed to initiate the implementation of reform program. The areas covered are:

1. $\mathrm{HR}$

2. Identification, Valuation and Transfer of Assets,

3. Identification and segregation of urban and rural feeders and zones and earmarking operational areas of WBREDC and WBSEB UD System and 
4. Metering, Billing, Collection, Electricity Accounting and System Loss Reduction of WBSEB

\section{Indian Electrricity Market}

India being a very vast country, several independent electricity markets may co-exist having their area of operation clearly demarcated from each other. In India, at the state level, the state power markets and at the regional/ national level, the regional national power markets may emerge. In the immediate future, after the enactment of Electricity Act 2003, it is felt that the prevailing conditions in the country are ripe only for wholesale competition and not for the retail competition.

\section{Evolution of Electricity Industry}

In the pre-independence time power sector consists of small private players to meet the local needs of the smaller area around them under the provision of Indian Electricity Act 1910. In 1947, the electricity industry in the UK was nationalized. India followed suit in 1948 and except for some pockets such as Mumbai, Kolkata, Ahmedabad and Surat. The entire industry was nationalized by virtue of the aforesaid Act of 1948, which laid down the structure of electricity industry in the independent India. This Act triggered the formation of State Electricity Boards (SEBs) to handle generation, transmission and distribution of electricity within the states. Subsequently central sector steeped in to support the National Load Dispatch Center (NLDC) is also planned to facilitate inter-regional transfer of power and for optimum scheduling and dispatch of electricity among the Regional Load Dispatch Centers (RLDCs). Given these various changes, the industry structure will be transformed from the current 'single-buyer model' to 'multi-buyer model'. In a multi-buyer model, the distribution entities are totally autonomous in procuring and dispatching their supply. This model would lead to better operation and lower cost to the end consumers. On an overall basis, Electricity Act 2003 is comprehensive and provides for progressive development of a market-based regime in Indian power sector through competition. The benefits will, however, start reflecting after a period of 4-5 years. Over the past two decades a number of countries have restructured their electricity industry by significantly reducing the government's role in the ownership and management of domestic electricity industries. It has seen as necessary conditions for increasing the efficiency of electric energy production and distribution, offering a lower price, higher quality and secured supply. The forces behind electric sector deregulation taking place worldwide are different in different countries.

\section{Recent Initiatives}

The Electricity Act 2003 makes thermal power are-licensed activity, freely permits captive generation and makes the setting up of state regulatory commissions mandatory. It recognizes the trading as a distinct commercial activity and suggests measures like preparation of National Electricity Policy for planned development of the sector. In line with the policy objectives, the act provides a drive to complete rural electrification and provide for management of rural distribution by cooperative societies, non-government organization, franchisees etc. The progressive policies would open new opportunities for setting up merchant generators, utilization of captive generation and electricity market development. A load dispatch center at the national level i.e. layers such as SEBs and utilities. It is a predetermined contracted transaction and there is non-existent of spot market. Currently, State load dispatch Centers (SLDCs) are carrying out the optimum scheduling of the state generating units and the RLDCs are responsible for scheduling of central sector generating units only. SLDCs send the requisition to the RLDCs against their entitlements out of available power from central sector generation (CGS) and the RLDCs allocate total available power to various states in the ratio of their entitlements. Day-to-day operation of the regional grid is carried out by RLDCs, which are under the operational control of Central Transmission Utility (CTU), i.e. Power Grid Corporation of India Ltd. all amount of power (about $2.5 \%$ of total generation).

IJEEI Vol. 5, No. 1, March 2017: $22-29$ 


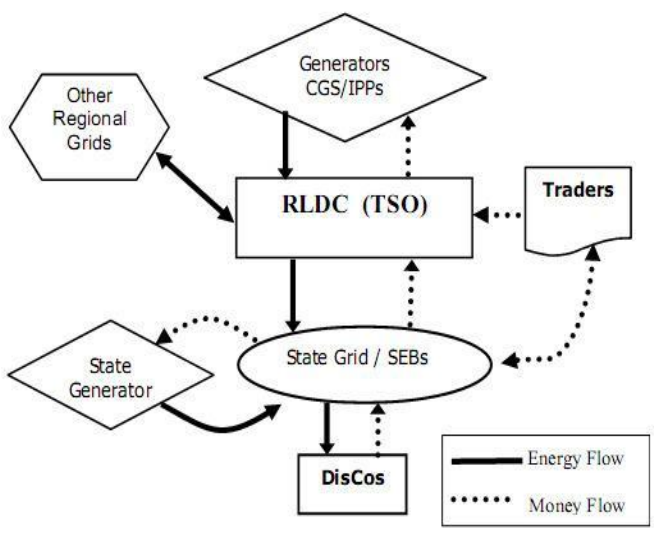

Figure 2. Current electricity market

\section{Recent Initiatives}

Apart from above, a small amount of generation is being traded at wholesale level through either bilaterally or with the help of power traders. But presently, trading is mostly restricted to players such as SEBs and utilities. Power trading has generated considerable interest among power players, as it is evident from the brisk line-up for licenses at Central Electricity Regulatory Commission (CERC). Presently there are seventeen trading licensees to whom CERC has granted license for inter-state trading in electricity. These traders apply for open access on behalf of suppliers and buyers to the nodal RLDC depending upon transaction requirement. CERC has made the regulations for open access in inter-state transmission and inter-state trading. The market structure of current Indian electricity industry is shown in Figure1, depicting energy flow and money flow separately.

\section{Key Issues}

The wholesale electric power trading in India, though a scent activity, is poised to develop a market and pave the way for creation of power exchange for economic pricing and optimal utilization of generation capacity. However, power trading has barely got off the ground in India, there are some major issues related to power trading, which need to be addressed for structural development of electricity market in India. These key issues include:

Non-existence of Power traders are just matchmakers. They are lacking formal market and realtime information because at present, no power exchange for power trading in the pattern of stock exchange really exists in the country. Trading is mostly restricted to Exchange: Presently power layers such as SEBs and utilities. It is a predetermined contracted transaction and there is non-existent of spot market.

a. Lack of Pricing Mechanism: CERC has fixed the trading profit margin as $0.02 \mathrm{Rs} / \mathrm{kWh}$ but there is no uniform method for price calculation of traded power. Traders simply negotiate the energy price between suppliers and purchasers and then add the trading margin. There is a need of market driven pricing mechanism.

b. Reliability of Supply and Off-take: Contractual obligations are not always honored. There is need of an institution/authority which can guarantee supply side delivery and buy side payment. A clearing system based on pledge accounts can minimize the risk for market participants.

c. Lack of Information: Traders are lacking equal and same time information about the market. Participants need information to evaluate his options and pick the most competitive deal. Setting up an online bulletin board offering real-time information for market participants would help.

d. Risk Management: Electricity market is highly price volatile because of dependence on fuel prices and network constraints during peak hours. Spot price variation in electricity market can be hedged with the help of risk hedging derivative instruments, which can be traded in financial markets for electricity. Competition is necessary for eradication of 
inefficiency but it should be introduced gradually in the phased manner. With the enactment of EA 2003, along with other recent initiatives, Government of India has outlined the counters of a suitable enabling framework.

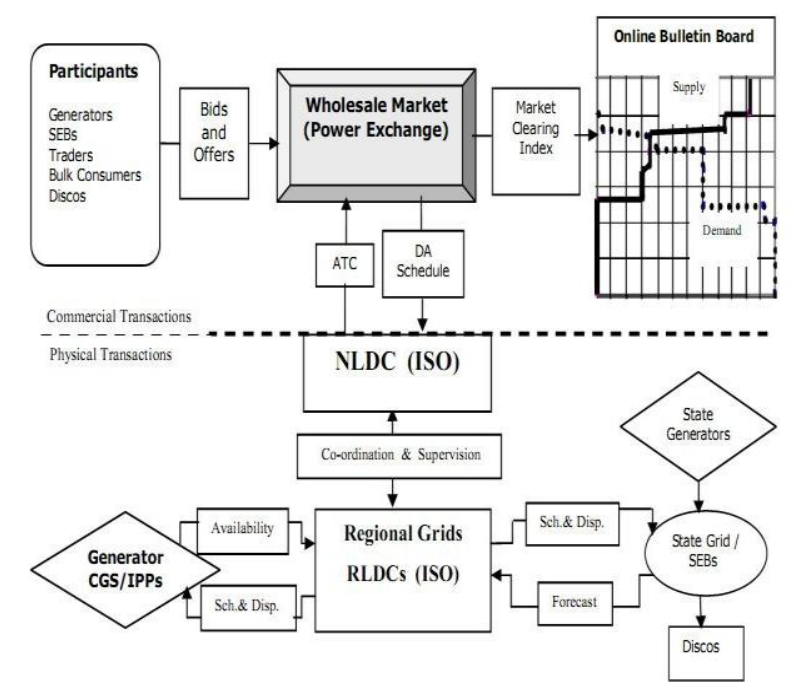

Figure 3. Proposed national electricity market

Figure 3 illustrates a simplified, theoretical model of the proposed national power market having different interactions between the relevant actors that participate in electricity market. The financial flows that result from electricity trade referred as 'commercial transactions' and the physical electricity flows referred as 'physical transactions' are depicted in upper and lower part of Figure 2 respectively.

In decentralized trading arrangement, $\mathrm{PX}$ has to be a separate entity from system operator, as an independent market operator. But PX should have strong co-ordination with system operators (NLDC/RLDCs) for ATC information, dispatch of DA schedules and imbalance settlement through UI mechanism.

\section{Conclusion}

Electricity reform process in India is already in action although at a slow pace. Several state electricity boards are being unbundled into three distinct corporations namely Generation, Transmission and distribution. The distribution system are being horizontally broken down into manageable Discos with separate accountability and privatized for better efficiency in metering, billing and revenue collection. The system operation functions at the regional/national level can be with central transmission utility, while state transmission utilities may manage load dispatch centers inline with TSO.

\section{References}

[1] Loi Lei Laai. Power System Restructuring and Deregulation. John Wiley \& Sons. England. 2002.

[2] Malik OP. Control Considerations in a Deregulated Electric Utility Environment. IEEE Canadian Review. 2000: 9-11.

[3] Yog Raj Sood, Narayana Prasad Padhy, HO Gupta. Wheeling of Power Under Deregulated Environment of Power System - A Bibliographical Survey. IEEE Transaction on Power Systems. 2001; 109(1).

[4] Khaparde SA, Kulkarni SV, Karandikar RG, Agalgaonkar AP. Role of Distributed Generation in Indian Scenario. Proceedings of South Asia Regional Conference. New Delhi, India. 2003.

IJEEI Vol. 5, No. 1, March 2017 : $22-29$ 
[5] Vindal SS, Saxena NS, Srivastava SC. Industry Structure Under Deregulated Wholesale Power Markets in India. Proceedings of International Conference on Present and Future Trends in Transmission and Convergence. New Delhi, India. December 2002.

[6] Government of India. The Electricity Act, 2003. New Delhi: The Gazette of India. 2003. Part I1 Section 3 Sub-section (ii).

[7] Kothari DP, Nagrath IJ. Power System Engineering. 2nd Edition. 